Journal of Management and Bussines (JOMB)

Volume 1, Nomor 1, Juni 2019

p-ISSN : 2656-8918

e-ISSN:2684-8317

IMAKPE

DOI : https://doi.org/10.31539/jomb.v1i1.600

\title{
PERAN CONSUMER AWARENESS DAN PERCEPTION TERHADAP BUYING INTEREST PADA PROPERTI SYARIAH
}

\author{
Fuji Safitri $^{1}$, Erry Sunarya ${ }^{2}$, R. Deni Muhammad Danial ${ }^{3}$ \\ Universitas Muhammadiyah Sukabumi ${ }^{1,2,3}$ \\ Email : Fujisafitri31@gmail.com ${ }^{1}$
}

\begin{abstract}
ABSTRAK
Tujuan penelitian ini yaitu untuk mengetahui pengaruh consumer awareness dan perception terhadap buying interest. Metode yang digunakan dalam penelitian ini adalah non propbability sampling yaitu convenience sampling dengan melakukan penyebaran kuesioner kepada calon pembeli properti syariah sebanyak 85 responden. Teknik analisis yang digunakan adalah analisis regresi linear berganda dan untuk uji hipotesis adalah uji statistik secara simultan (uji F). Hasil penelitian, hasil uji F menunjukkan bahwa nilai sig $0,000<0,05$ yang berarti bahwa secara bersama-sama consumer awareness (X1) dan perception (X2) berpengaruh signifikan terhadap buying interest (Y). Berdasarkan uji koefisien determinasi bahwa diperoleh sebesar 0,749 maka diartikan bahwa kontribusi pengaruh yang diberikan consumer awareness dan perception terhadap buying interest adalah 74,9\%, maka hanya sebesar $25,1 \%$ dipengaruhi oleh variabel lain yang tidak dijelaskan dalam penelitian ini. Simpulan, peran consumer awareness dan perception secara bersama-sama memiliki pengaruh signifikan terhadap buying interest
\end{abstract}

Kata Kunci : Consumer Awareness, Perception, Buying Interest

\begin{abstract}
The purpose of this study is to study the interaction of consumer awareness and perception of buying interests. The method in this study uses non propbability sampling, namely convenience sampling by distributing questionnaires to prospective sharia property buyers. The analysis technique used is multiple linear regression analysis, and for hypothesis testing is a statistical test simultaneously ( $F$ test). F test results show a sig value of 0,000<0,05 which means that together Consumer Awareness (X1) and Perception (X2) have a significant effect on Buying Interests (Y). Based on the test of the coefficient of determination of 0.749 can be interpreted according to the contribution given Consumer awareness and Perception of Buying Interest is $74.9 \%$, then by $25.1 \%$ can be changed by other variables that are not necessary in this study.
\end{abstract}

Keywords : Consumer Awareness, Perception dan Buying Interest 


\section{PENDAHULUAN}

Pertumbuhan bisnis di sektor properti menjadi sorotan penting bagi sebagian masyarakat yang sedang membutuhkan tempat tinggal, sehingga masyarakat dapat lebih menelaah agar tepat didalam menentukan sebuah pilihan, karena tempat tinggal merupakan wadah yang berharga untuk pembentukan karakater dan peningkatan kualitas diri manusia.

Properti menjadi sebuah usaha yang menjanjikan dan memberi keuntungan yang besar dengan jangka waktu panjang. Sektor perumahan properti dapat memiliki peranan yang penting didalam menumbuhkan perekonomian, diduga bahwa permintaan terhadap properti bisa menjadi meningkat jika ditandai dengan adanya pertambahan penduduk, seperti halnya Kota Sukabumi yang setiap tahun selalu mengalami peningkatan. Buying interest merupakan minat atau ketertarikan yang dimiliki konsumen untuk bisa membeli produk atau jasa tertentu, sehingga penting diperhatikan untuk membantu meningkatkan penjualan pada perusahaan.

Persaingan yang terjadi dalam dunia usaha semakin ketat, untuk bisa meningkatkan buying interest perusahaan harus menumbuhkan (consumer awareness) kesadaran konsumen, agar konsumen dapat berkomitmen untuk memilih properti syariah. Maka keselarasan sebuah bisnis dan syariat agama dapat membantu juga untuk kelancaran bisnis, karena menghindari riba yang hukumnya haram dalam KPR atau properti.

Perception atau persepsi yang baik dan dimiliki oleh konsumen bisa mendorong dirinya pada (buying interest) ketertarikan atau minat untuk bisa membeli (Darmadi, 2003). Dengan begitu target penjualan properti syarih dapat tercapai atau meningkat. Maka persepsi merupakan proses dimana seseorang memilih, mengatur dan menerjemahkan masukan informasi yang diterima untuk menciptakan gambaran dunia yang lebih berarti (Amstrong, 2008).

PT Bangun Rumah Syariah atau properti syariah merupakan kontraktor dan developer dengan sistem yang digunakan adalah membangun rumah di tanah yang konsumen miliki dengan sistem pembayaran adalah dicicil. Dalam penelitian ini dapat mengatahui tentang sebuah kesadaran yang dapat berpengaruh atau tidak pada minat beli properti dengan basis syariah. 


\section{KAJIAN TEORI}

\section{Consumer Awareness}

Consumer awareness adalah suatu kesadaran konsumen yang dapat mempengaruhi dirinya didalam memahami sesuatu. Konsumen pun merupakan makhluk sosial yang tak luput dengan adanya sebuah interaksi sehingga hal tersebut cenderung lebih besar akan terpapar informasi dari berbagai pihak. Karena kesadaran timbul sacara internal dalam diri manusia atas sesuatu yang dirasakannya atau di persepsikannya.

Menurut Sokanto (dalam Nuidayat, 2016) bahwa kesadaran konsumen dapat dibentuk melalui tiga dimensi, yaitu:

1. Pengetahuan (knowledge) mengacu pada wawasan atau sesuatu hal yang diketahui oleh konsumen, pengetahuan didapat ketika seseorang menerima sebuah objek dengan indera yang dimilikinya, sehingga pengetahuan tersebut dapat diproses oleh dirinya untuk dapat dimanfaatkan, diamalkan atau hanya di simpan sendiri dalam diri. Pengetahuan dipengaruhi oleh indikator berikut: a) faktor eksternal meliputi, kematangan seseorang dalam berpikir lebih rasional atas informasi yang diterima, lalu hubungan social atau sebuah pandangan umum yang diperbincangkan di masyarakat juga dapat mempengaruhi, b) faktor internal, berdasarkan keteguhan seseorang dalam mencari tahu sesuatu yang baik atau buruk baginya. Serta lebih mengutamakan kebutuhannya daripada keinginannya.

2. Sikap merupakan respon atau sebuah reaksi atas stimulus atau objek. Dengan kata lain sikap adalah sebuah kesediaan seseorang untuk bertindak.

3. Tindakan, tentunya sebuah tindakan menjadikan praktek nyata seseorang dalam menerapkan kesadaran yang dirasakannya, ketika seseorang merasa bahwa memiliki kesadaran atas sesuatu maka dibalik kesadaran tersebut dapat mendorong seseorang didalam melakukan tindakan yang lebih positif. Konsumen yang memiliki kesadaran atas suatu hal cenderung akan meninggalkan produk lama jika dirasa itu bukan pilihan yang tepat untuknya.

\section{Perception}

Perception merupakan sebuah pandangan yang dimiliki oleh seseorang, sehingga dapat dengan mudah memiliki deskripsi tersendiri atau dapat menerjemahkan 
secara langsung atas stimulus yang telah diterima oleh dirinya, dengan persepsi yang tentunya berbeda dari setiap orang. Perbedaan pandangan manusia didalam mengartikan sesuatu hal tentunya dipengaruhi banyak faktor diantaranya sudut pandang setiap individu, baik atas pengetahuan luas yang dimilikinya, maupun dari hubungan sosial seseorang. Persepsi merupakan proses dimana seseorang mengatur dan menerjemahkan informasi atau masukan yang diterimanya untuk menciptakan gambaran dunia yang lebih berarti (Amstrong, 2008). Pembentukan persepsi menurut (Thoha, 2003) antara lain:

1. Faktor yang berasal dari dalam dirinya atau internal yaitu pembentukan persepsi terhadap sesuatu yang dipersespsikan atas perasaan, kepribadian individu.

2. Faktor yang berasal dari luar dirinya atau eksternal seperti pembentukan persepsi atas latar belakang, informasi yang diperoleh, hal-hal baru dan familiar atau ketidak asingan suatu objek.

\section{Buying interest}

Buying interest adalah ketertarikan seseorang untuk melakukan tindakan pembelian suatu produk atau jasa tertentu atas kesesuaian antara produk yang diinginkan dan sistem penjualan yang diterapkan oleh perusahaan. Konsumen dapat tertarik dengan produk atau jasa yang ditawarkan pemasar sehingga menimbulkan tindakan pembelian atau berpindah kepada produk yang baru. Seberapa besar kemungkinan konsumen membeli suatu merek atau seberapa besar kemungkinan konsumen untuk berpindah dari satu merek ke merek lainnya (keller, 2012). Adapun menurut (Britt, 2012) mengemukakan bahwa minat beli memiliki aspek antara lain :

1. Perhatian (attention). Adanya perhatian yang besar terhadap produk/jasa yang diinginkan oleh konsumen.

2. Ketertarikan (interest). Timbul rasa ketertarikan konsumen atas produk atau jasa tersebut.

3. Keinginan (desire). Kemudian timbul rasa ingin memiliki produk tersebut.

4. Keyakinan (conviction). Setelah itu akan timbul keyakinan pada diri konsumen terhadap produk jasa tersebut yang menimbulkan tindakan akhir.

5. Keputusan (action) yaitu untuk memperolehnya melalui tindakan membeli. 


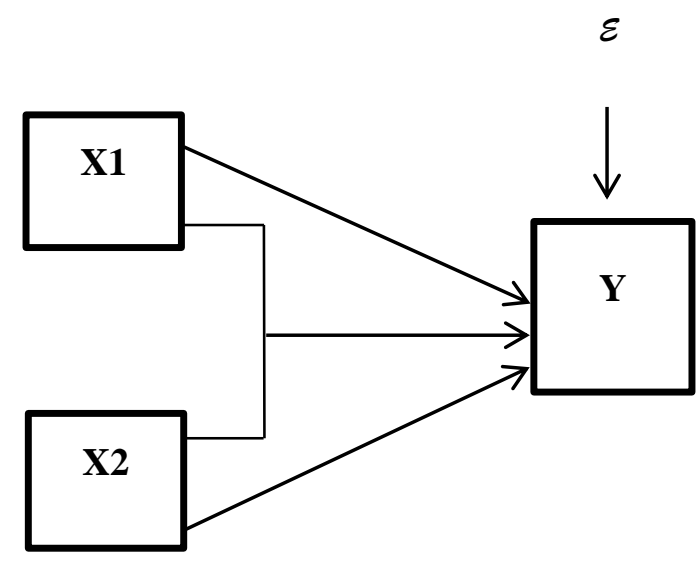

Gambar 1 Kerangka Pemikiran

Keterangan :

$\mathrm{X} 1=$ Consumer Awareness

$\mathrm{X} 2=$ Perception

$\mathrm{Y} \quad=$ Buying Interest

$\varepsilon \quad=$ Faktor lain, diluar penelitian ini

\section{METODE PENELITIAN}

Lokasi yang dijadikan tempat penelitian adalah PT Bangun Rumah Syariah di Jalan Bhayangkara no.24, Gn. Puyuh, Kota Sukabumi, Jawa Barat, Indonesia. Populasi didalam penelitian ini adalah calon pembeli BRS atau Bangun Rumah Syariah, dimana populasi ini mengcakup semua orang yang pernah melakukan komunikasi dengan pemasar BRS dengan beragam jenis usia, pekerjaan, hingga pendapatan.

Adapun metode pengumpulan data pada penelitian ini yaitu non probability sampling yaitu dengan menggunakan accidental atau convenience sampling didalam mengumpulkan data. Peneliti menggunakan teknik ini agar dapat memudahkan dan pengambilan sampel dilakukan secara kebetulan namun didasari dengan ketentuan tertentu misalnya aksesibilitas nyaman dan ketentuan untuk memilih konsumen. Sampel yang digunakan dalam penelitian ini sebanyak 85 orang responden. 


\section{HASIL PENELITIAN}

Dalam melaksanakan rangkaian penelitian ini, peneliti menggunakan bantuan perangkat lunak yaitu SPSS versi 24.

Tabel 1

Koefisien Korelasi

\begin{tabular}{lrrrr}
\hline \multicolumn{4}{c}{ Model Summary } \\
\hline Model & $\mathrm{R}$ & R Square & Adjusted R Square & $\begin{array}{c}\text { Std. Error of the } \\
\text { Estimate }\end{array}$ \\
\hline 1 & $.865^{\mathrm{a}}$ & .749 & .743 & 2.39463 \\
\hline
\end{tabular}

a. Predictors: (Constant), Perception (x2), Consumer Awareness (x1)

Berdasarkan table diatas dapat dilihat pada kolom R, diketahui bahwa korelasi variable X1 consumer awareness dan Perception adalah sebesar 0,865. Dalam melakukan perhitungan koefisien determinasi, menurut sugyono Menurut (Sugiyono, 2014) dapat menggunakan rumus sebagai berikut:

$$
\mathrm{Kd}=\mathrm{r}^{2} \times 100 \%
$$

Keterangan :

$\mathrm{Kd}=$ Koefisien Determinasi

$\mathrm{r} \quad=$ Koefisiesn Korelasi

Dengan perhitungan sebagai berikut:

$$
\begin{array}{rlr}
\mathrm{Kd} & =\mathrm{r}^{2} & \mathrm{x} 100 \% \\
& =(0,865)^{2} & \mathrm{x} 100 \% \\
& =0,749 & \\
& =74,9 \% &
\end{array}
$$

Berdasarkan perhitungan koefisien determinasi yang telah peneliti lakukan, maka diketahui bahwa nilai $\mathrm{Kd}=74,9 \%$ sedangkan sisanya adalah $25,1 \%$ yang didapatkan dari $(100 \%-74,95 \%=25,1 \%)$ merupakan faktor yang tidak diteliti didalam 
penelitian ini. Maka dapat ditarik kesimpulan bahwa variabel (X1) consumer awareness dan (X2) perception terhadap (Y) buying interest adalah kuat.

Table 2

Regresi Linear Berganda

\section{Coefficients $^{\mathrm{a}}$}

\begin{tabular}{|c|c|c|c|c|c|c|}
\hline \multirow[b]{2}{*}{ Model } & & \multicolumn{2}{|c|}{$\begin{array}{l}\text { Unstandardized } \\
\text { Coefficients }\end{array}$} & \multirow{2}{*}{$\begin{array}{c}\begin{array}{c}\text { Standardized } \\
\text { Coefficients }\end{array} \\
\text { Beta }\end{array}$} & \multirow[b]{2}{*}{$\mathrm{t}$} & \multirow[b]{2}{*}{ Sig. } \\
\hline & & $\mathrm{B}$ & Std. Error & & & \\
\hline \multirow[t]{3}{*}{1} & (Constant) & -3.013 & 1.432 & & -2.105 & .038 \\
\hline & $\begin{array}{l}\text { Consumer Awareness } \\
(\mathrm{x} 1)\end{array}$ & -.022 & .071 & -.020 & -.307 & .760 \\
\hline & Perception (x2) & 1.431 & .106 & .875 & 13.553 & .000 \\
\hline
\end{tabular}

a. Dependent Variable: Buying Interest (y)

Berdasarkan ouput perhitungan dari SPSS diatas, maka persamaan regresi berganda, yaitu:
a $\quad=-3.013$
b1 $=-0,022$
$\mathrm{b} 2=1.431$

Adapun persamaan regresi linear berganda yang didapat atas dua predikator (X1 dan X2) yaitu :

$\mathrm{Y}=-3.013-0,022 \mathrm{X}_{1}+1.431 \mathrm{X}_{2}$

1. Konstanta sebesar -3.013; Buying interest (Y) bernilai -3.013 jika consumer awareness (X1) dan perception (X2) nilainya adalah 0 .

2. Koefisien regresi variabel consumer awareness (X1) adalah -0,022. Artinya jika variabel independen yang lain nilainya tetap dan consumer awareness mengalami peningkatan 1\%, maka buying interest (Y) akan mengalami penurunan sebesar $0,022 \mathrm{X}_{1}$.

3. Koefisien regresi variabel perception (X2) sebesar 1.431; artinya jika variabel lain nilainya tetap dan perception mengalami peningkatan atau kenaikan 1\%, maka buying interest (Y) akan mengalami peningkatan juga sebesar 1.431. Dalam koefisien yang bernilai positif artinya terjadi hubungan positif antara variabel 
perception dengan buying interest. Jika perception menjadi naik maka buying interest akan semakin meningkat.

Tabel 3

Hasil uji F

\begin{tabular}{llcrrrr}
\multicolumn{7}{c}{ ANOVA $^{\text {a }}$} \\
Model & Sum of Squares & Df & Mean Square & F & Sig. \\
\hline 1 & Regression & 1401.014 & 2 & 700.507 & 122.1 & $.000^{b}$ \\
& & & & & 62 & \\
\cline { 2 - 7 } & Residual & 470.209 & 82 & 5.734 & \\
\cline { 2 - 7 } & Total & 1871.224 & 84 & & & \\
\hline
\end{tabular}

a. Dependent Variable: Buying Interest (y)

b. Predictors: (Constant), Perception (x2), Consumer Awareness (x1)

Berdasarkan tabel yang ada diatas bahwa didapatkan nilai sig $0,000<0,05$ dan nilai $\mathrm{F}_{\text {hitung }} 122.162>\mathrm{F}_{\text {tabel }}$ 4,87 maka hal ini dapat dikatakan bahwa consumer awareness dan perception secara simultan berpengaruh terhadap buying interest.

\section{PEMBAHASAN}

Penelitian ini dilakukan untuk mengetahui terdapatnya pengaruh antara variabel yang diteliti antara variabel consumer awareness dan perception terhadap buying interest. Dalam hal minat beli, dimana untuk bisa meningkatkannya tidak luput dari perilaku konsumen yang terjadi, seorang pemasar haruslah bisa mempelajari perilaku konsumen dengan baik karena hal penting dalam sebuah bisnis. Perilaku konsumen menggambarkan cara individu didalam mengambil keputusan untuk memanfaatkan sumber daya mereka yang guna membeli barang-barang yang berhubungan dengan konsumsi (Kanuk, 2008).

Menurut (Evan, 2007) bahwa perception muncul ketika banyaknya stimulus yang masuk pada indera manusia lalu memproses dirinya sehingga menjadikannya dapat menyadari tentang objek terterntu. Namun dalam arti sempit perception adalah proses ketika seseorang menjadi sadar. Sehingga kesadaran dan persepsi dapat berkaitan satu sama lainnya. Adapun dalam mendorong minat beli juga maka dapat didorong dari sebuah kesadaran, kesadaran selalu berhubungan dengan faktor internal pada diri 
seseorang seperti pengetahuan yang dimilikinya terhadap sesuatu. Kesadaran sangat erat kaitannya dengan pengetahuan (Martajaya, 2016).

Maka hasil yang diperoleh atas penelitian ini yaitu untuk $\mathrm{H} 1$ diterima dan $\mathrm{H} 0$ ditolak, hal tersebut dapat dibuktikan dari pengujian yang sudah dilakukan oleh peneliti bahwa nilai sig $0,000<0,05$ dan untuk nilai $F_{\text {hitung }} 122.162>F_{\text {tabel }} 4,87$. Artinya yaitu terdapat pengaruh secara simultan (bersama-sama) consumer awareness dan perception terhadap buying interest.

\section{SIMPULAN}

Berdasarkan pembahasan yang telah diuraikan serta hasil analisis yang telah dilakukan oleh peneliti maka dapat diabil kesimpulan bahwa variabel penelitian consumer awareness dan perception secara bersama-sama (simultan) memiliki pengaruh signifikan terhadap buying interest. Kontribusi pegaruh yang diberikan pun cukup besar antara consumer awareness dan perception terhadap buying interest dalam peneltian ini, sehingga berkaitan erat dalam meningkatkan minat beli (buying interest )pada produk atau jasa.

\section{DAFTAR PUSTAKA}

Amstrong, K. d. (2008). Prinsip-prinsip Pemasaran. Jakarta: Erlangga.

Britt, L. d. (2012). Measuring Advertising Effectiveness. New York: McGraw Hill. Darmadi, D. (2003). Invasi Pasar dengan Iklan yang Efektif. Jakarta: Gramedia. Evan, B. d. (2007). Manajemen Ritel. Jakarta: Erlangga.

Kanuk, S. d. (2008). Perilaku Konsumen. Jakarta: Indeks. keller. (2012). Manajemen Pemasaran. Jakarta: Erlangga.

Martajaya, A. (2016). Analisis pengaruh kesadaran, perhatian, minat dan tindakan pada keputusan pembelian produk body shop Bandar Lampung. 3.

Sekaran, U. (2006). Metode Penelitian Untuk Bisnis . Jakarta: Salemba.

Sugiyono. (2014). Metode Penelitian Pendekatan Kuantitatif. Bandung: Alfabeta.

Thoha. (2003). Perilaku Organisasi Konsep Dasar dan Aplikasinya. Jakarta: PT Raja Grafindo Pesada. 